\title{
Yield, quality and drought sensitivity of tomato to water deficit during different growth
}

\author{
stages \\ Jintao Cui ${ }^{1 \oplus}$, Guangcheng Shao ${ }^{1 *} \odot$, Jia Lu$^{1} \odot$, Larona Keabetswe ${ }^{1 \oplus}$, Gerrit Hoogenboom ${ }^{2} \odot$
}

${ }^{1}$ Hohai University/Ministry of Education, College of Agricultural Engineering - Key Lab. of Efficient IrrigationDrainage and Agricultural Soil-Water Environment in Southern China, 1 Xikang Road - 210098 - Nanjing - China.

2University of Florida/Institute for Sustainable Food Systems - Dept. of Agricultural and Biological Engineering, FL 32611 - Gainesville - USA.

*Corresponding author <sgcln@hhu.edu.cn>

Edited by: Daniel Scherer de Moura

Received November 22, 2018

Accepted February 26, 2019

\begin{abstract}
In areas where the supply of water for irrigation is limited, tomato production is often subject to drought stress. In order to investigate the drought sensitivity of tomato (Lycopersicon esculentum Mill.) yield and quality during different growth stages, field and pot experiments were conducted in a high tunnel in southern China during the 2013 and 2016 growing seasons. The experiments consisted of four treatments. Crops were drip-irrigated to $100 \%$ of field capacity at all growth stages divided into treatment $\mathrm{T} 1$ (control) and the treatment group T2, T3 and $\mathrm{T} 4$ receiving half the amount of irrigation as $\mathrm{T} 1$ when the soil water content reached $70 \%$ of field capacity, the vegetative phase (stage I) T2, the flowering and fruit development phase (stage II) $\mathrm{T} 3$, and the fruit ripening phase (stage III) T4. Compared to the control treatment, drought stress at stages II and III caused a decrease in yield of $13 \%$ and $26 \%$, respectively. Fruit firmness and color index were positively affected by drought stress, while fruit water content and shape index did not show any differences between treatments. Taste and nutritional quality parameters, such as total soluble solids, soluble sugar, organic acids and vitamin $C$ improved in response to limited water supply $(p \leq 0.05)$. Despite having a negative effect on fruit yield, drought stress applied at stage III tended to enhance fruit quality traits. This study found that applying drought stress at stage I can be a positive management approach as it saves water and has fewer negative effects compared to applying drought stress at the other critical growth stages, thereby minimizing the adverse effects of drought stress.
\end{abstract}

Keywords: deficit irrigation, sensitivity index, irrigation management, high tunnel

\section{Introduction}

Tomato (Lycopersicon esculentum Mill.) is one of the most popular vegetable crops in the world and has the greatest area under cultivation compared to other vegetables (Nangare et al., 2016). Tomato production in southern China is adversely affected by abiotic stresses such as drought, rainstorms, heat, and salinity (Shao et al., 2015a). Heavy rain and high temperatures that occur during the summer season increase the incidence of blossom end rot and fruit cracking (Peet, 1992), resulting in poor fruit quality and a decrease in yield (Qi et al., 2003). High tunnel technology in such conditions is considered the most effective means of protecting crops against heavy rainfall as well as improving crop yield and fruit quality (William, 2009; Shao et al., 2015b).

Deficit irrigation is an agricultural water management strategy by which crops are exposed to a level of drought stress either during a certain period of time or during the entire growing season (Topcu et al., 2007). Studies of deficit irrigation for tomato have shown mixed results in terms of fruit yield and quality. $\mathrm{Pu}$ lupol et al. (1996) found that drought stress resulted in a drastic reduction in dry mass yield, while other studies reported no adverse effects on yield and fruit quality for a field-grown processing cultivar (Patanè et al., 2011; Nangare et al., 2016). Chen et al. (2014) showed that tomato yield was mainly affected by drought stress that occurred throughout the course of fruit growth and maturation, but quality was sensitive to drought stress during the fruit ripening stage. To the best of our knowledge, to date only a limited number of experiments have studied the effect of deficit irrigation on fruit yield and qualitative characteristics at various stages when tomatos are grown in high tunnels whereby the growth periods and micro-climates were significantly different from open-field and greenhouse conditions (William, 2009; Shao et al., 2015a). Therefore, it is essential to understand the requirements for the timing of irrigation to meet the demand for tomato production grown in high tunnels with a limited water supply.

The overall goal of this study was to investigate the quantitative relationship between tomato yield, quality, and water consumption grown in high tunnels under water-limiting conditions. Specific objectives were to evaluate the effect of deficit irrigation on tomato yield, quality and water use efficiency and to identify the primary drought sensitive period of tomato on yield and quality traits.

\section{Materials and Methods}

\section{Plant material and growth conditions}

Experiments were conducted in Nanjing, Jiangsu, China, $\left(31^{\circ} 57^{\prime} \mathrm{N}, 118^{\circ} 50^{\prime} \mathrm{E}\right.$, and altitude $144 \mathrm{~m}$ above MSL), during the tomato-growing season in 2013 and 2016. The study area had a subtropical, humid climate with an annual mean temperature of $15.7{ }^{\circ} \mathrm{C}$. The 
mean annual precipitation was approximately $1,072.9$ $\mathrm{mm}$ and mean annual pan evaporation $1,472.5 \mathrm{~mm}$. The experimental field in the high tunnel was $18.0 \mathrm{~m}$ in a north-south orientation and $7.8 \mathrm{~m}$ in an east-west orientation with a planting area of $140.0 \mathrm{~m}^{2}$ (Figure 1). The tomato seedlings were transplanted into 12 plots with a surface area of $4.5 \mathrm{~m}^{2}(1.5 \times 3.0)$ in 2013 and 12 pots with a surface area of $0.2 \mathrm{~m}^{2}\left(\pi \times 0.25^{2}\right)$ at a depth of $0.7 \mathrm{~m}$ in 2016 . The tomato cultivars, duration of the individual growth phases, and soil characteristics for the top 0-30 cm soil layer for the two growing seasons are given in Table 1 . The mean daily temperature and relative humidity in the high tunnel were $25.5^{\circ} \mathrm{C}$ and $66 \%$ for the 2013 season, and $24.0{ }^{\circ} \mathrm{C}$ and $70 \%$ for the 2016 season (Figure 2A and B). Eighteen plants were evenly transplanted in each plot in the high tunnel with a spacing of $0.6 \mathrm{~m}$ between rows and $0.5 \mathrm{~m}$ between plants for the 2013 season. The middle row was

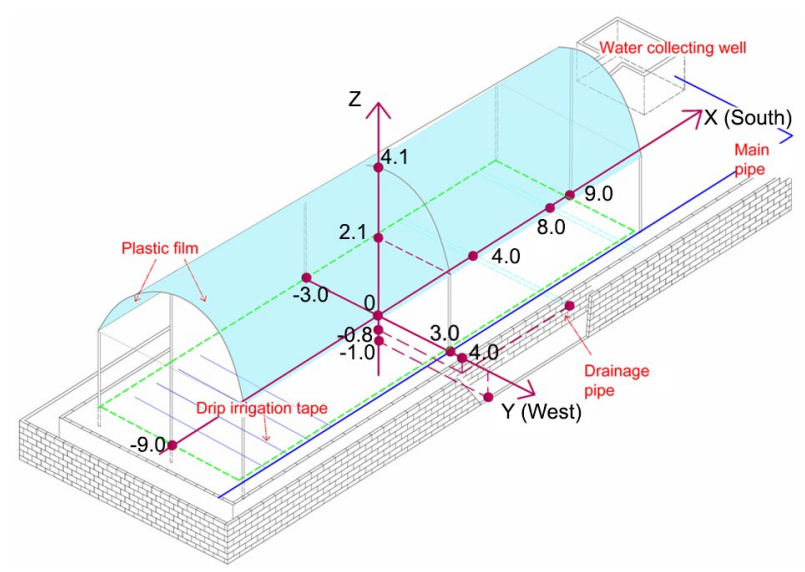

Figure 1 - Diagrammatic representation of the experimental site under a high tunnel condition. The origin of coordinate axis is at the center of the field under the high tunnel. Numeric values are given in meters.

Table 1 - Tomato cultivars, duration of growth phases, and soil characteristics for the $0-30 \mathrm{~cm}$ soil layer for the 2013 and 2016 growing seasons.

\begin{tabular}{lcc}
\hline \multirow{2}{*}{ Characteristics } & \multicolumn{2}{c}{ Season } \\
\cline { 2 - 3 } Cultivars & Asian Fenwang & Zhongshu N0.4 \\
Transplanting date & $16 \mathrm{Apr}$ & $19 \mathrm{Apr}$ \\
Harvest date & $1 \mathrm{Aug}$ & $3 \mathrm{Aug}$ \\
Stage I & $25 \mathrm{Apr} 23 \mathrm{May}$ & $28 \mathrm{Apr} \sim 27 \mathrm{May}$ \\
Stage II & 24 May 24 June & 28 May 30 June \\
Stage III & 25 June 1 Aug & 1 July 3 Aug \\
Dry bulk density $\left(\mathrm{g} \mathrm{cm}^{-3}\right)$ & 1.35 & 1.33 \\
Field capacity $(\%)$ & 34 & 33 \\
Organic matter $(\%)$ & 0.72 & 0.75 \\
Total Nitrogen $\left(\mathrm{g} \mathrm{kg}^{-1}\right)$ & 0.91 & 0.93 \\
Total Phosphorus $\left(\mathrm{g} \mathrm{kg}^{-1}\right)$ & 0.34 & 0.42 \\
Total Potassium $\left(\mathrm{g} \mathrm{kg}^{-1}\right)$ & 0.54 & 0.71 \\
\hline
\end{tabular}

harvested for production measurement while the other rows were border rows. For 2016, plants in each trial were grown in pots filled with a clay topsoil obtained from the experimental field. In all treatments for both 2013 and 2016, $500 \mathrm{~kg} \mathrm{ha}^{-1}$ of compound fertilizer (N: $\mathrm{P}_{2} \mathrm{O}_{5}: \mathrm{K}_{2} \mathrm{O}, 15 \%: 15 \%: 15 \%$ ) was uniformly applied as basal fertilizer prior to transplanting. Transplanting was at the six-leaf stage, accompanied by light irrigation to ensure survival of the tomato seedlings.

\section{Treatments and experiment design}

The four treatments were replicated three times in a randomized complete block design in the high tunnel. The plants were irrigated to $100 \%$ of field capacity for all growth stages for treatment T1 (control). The experimental treatments were based upon the growth stages as follows: the vegetative stage (stage I) was from transplanting to first fruit set; the flowering and fruit development stage (stage II) from first fruit set to first fruit maturity; and the fruit ripening stage (stage III) from first fruit maturity to final harvest. Further details can be found in Chen et al. (2013). The three drought treatments received half the amount of irrigation as T1 but at differing stages: treatment T2 during stage I, T3 during stage II, and T4 during stage III. Except for the stages that were subject to drought stress, irrigation amounts were the same as the control (Figure 3). Irrigation was applied when the soil moisture content of T1 reached $70 \%$ of field capacity via drip irrigation and the amount was recorded using a water gauge in 2013. The drip irrigation method was also implemented for the crops grown in pots in 2016, and the amount recorded by manually weighing each individual pot. The irrigation treatments were initiated seven days after transplanting and terminated for all treatments ten days prior to the end of final harvest. To avoid any effect of groundwater, drainage pipes for all plot treatments were installed at a depth of $0.6 \mathrm{~m}$ in 2013.
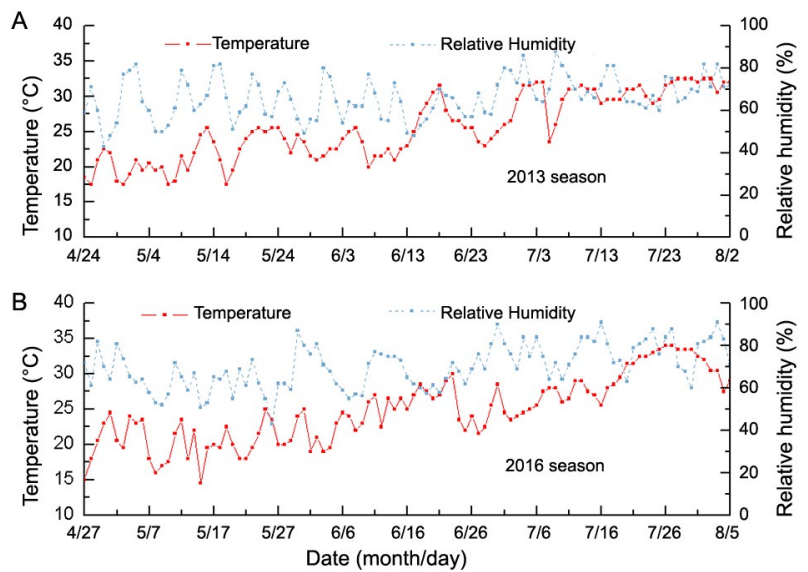

Figure 2 - Average daily air temperature and relative humidity in the high tunnel during the 2013 (A) and 2016 (B) growing seasons. 


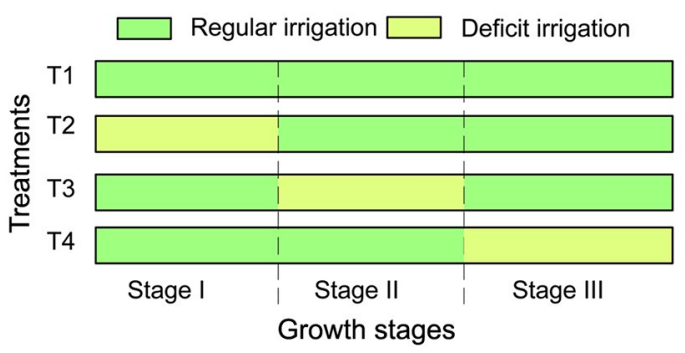

Figure 3 - Description of the different tomato irrigation treatments. Stage I is vegetative phase; stage $\|$ is flowering and fruit development phase; stage III is fruit ripening phase. The irrigation lower and upper limit of regular irrigation is $70 \%$ and $100 \%$ of field capacity. The deficit irrigation was applied at $50 \%$ water supply of $\mathrm{T} 1$ treatment. The $\mathrm{T} 1$ treatment is the control.

\section{Measurements of yield and quality}

During the ripening period, the fruits were harvested in each plot (2013) and from each pot (2016) to determine the individual fruit weight, fresh yield and subsequent quality measurements. The fruits were separated into marketable and cull categories (U.S. Department of Agriculture, 1991). The cull fruits were further classified based on the predominant reason for culling as follows: blossom-end rot, cracked, misshapen, sunburned, insect damaged, colored while still too small (typically with a diameter $\leq 2 \mathrm{~cm})$, and a miscellaneous category for the remainder of the fruit (Kahn and Damicone, 2008).

For each harvest, the weight, volume, shape and color of all harvested fruit for each treatment were measured. The shape index was calculated using the ratio of the vertical to the horizontal diameter, as measured with a Vernier caliper. Fruit color was determined with a spectrophotometer. The color index $(\mathrm{CI})$ was calculated by the following equation:

$$
C I=\frac{2000 a}{L \sqrt{a^{2}+b^{2}}}
$$

where $C I$ is the fruit color index; $L$ the lightness ranging from black to white; $a$ a scale ranging from green to red; and $b$ a scale ranging from blue to yellow.

Twenty tomatos were randomly selected from the marketable fruit for physical and chemical quality measurement as described by Shao et al. (2015a). The soil water content was monitored by a time domain reflectometer. Irrigation water use efficiency (IWUE) was calculated by dividing the total fresh yield by the amount of water used for irrigation, and the irrigation water productivity (IWP) was identified as the ratio of the marketable fresh yield to the amount of irrigation that was applied (Nangare et al., 2016).

\section{Drought sensitivity analysis}

The actual crop evapotranspiration was estimated based on the soil water balance method. The change in soil water content from the top 0 to $50 \mathrm{~cm}$ soil layer dur- ing the growing season was used to estimate crop water consumption as follows (Allen et al., 2011):

$E T=P+I+\Delta W-R-D$

where $E T$ is evapotranspiration $(\mathrm{mm}) ; P$ precipitation $(\mathrm{mm}) ; I$ the irrigation amount $(\mathrm{mm}), \Delta W$ the soil water storage variation $(\mathrm{mm}) ; R$ the surface runoff $(\mathrm{mm})$, and $D$ the deep drainage $(\mathrm{mm})$. There was no precipitation or runoff in the high tunnel, so $P$ and $R$ were both zero. No drainage was observed from the drainage pipes in the 2013 season, and the drainage outlets of the pots used in 2016 were closed, therefore, $D$ was also set to zero. Consequently, the simplified resultant of Eq. (2) was:

$E T=I+\Delta W$

The number of stress days (SD) was calculated from Eq. (4) in accordance with Mogensen et al. (1985):

$S D=\sum_{i=1}^{n} S D(i)=\sum_{i=1}^{n}\left[1-\frac{E T_{a i}}{E T_{c k i}}\right] \times N_{i}$

where $E T_{a i}$ and $E T_{c k i}$ are actual crop evapotranspiration at the growth stage ' $i$ ' of deficit and full-irrigation treatments, respectively; $N_{i}$ the number of days at the growth stage ' $i$ '; $i$ the $i$ th growth stage; and $n$ the number of growth stages.

The relative yield reduction $(F y)$ was given as

$F y_{i}=1-Y_{i} / Y_{c k}$

where $Y_{c k}$ and $Y_{i}$ are the yield of the full and deficit irrigation treatments, respectively; $F y_{i}$ the yield drought sensitivity during growth stage ' $i$ '; and $i$ the $i$ th growth stage.

The yield response factor $(K y)$ developed was calculated from equation (6):

$1-Y_{i} / Y_{c k}=K y_{i} \cdot\left[1-E T_{i} / E T_{c k}\right]$

where $K y_{i}$ is the yield response factor during the growth stage ' $i$ ', and the other parameters are as previously defined.

Similarly, the relative quality improvement $(F q)$ was given as

$F q_{i}=Q_{i}^{\prime} / Q_{c k}-1$

where $Q_{c k}$ and $Q_{i}$ are the fruit quality of the full and deficit irrigation treatments, respectively; $F q_{i}$ is the fruit quality improvement during growth stage ' $i$ ', and $i$ the $i$ th growth stage.

The quality response factor $(K q)$ was given as

$Q_{i} / Q_{c k}-1=K q_{i} \cdot\left[1-E T_{i} / E T_{c k}\right]$

where $K q_{i}$ is the fruit quality response factor during the growth stage ' $i$ ', and the other parameters are as previously defined. 


\section{Statistical analysis}

All statistical analyses in this study were conducted using the Statistical Product and Service Solutions Version 16.0 software package. The data were evaluated using one-way analysis of variance (ANOVA), and the least significant differences (LSD) test at $p \leq 0.05$ was used to determine the statistical differences between the means of each treatment. The data were presented in terms of means \pm standard errors $(\mathrm{SE})$.

\section{Results}

\section{Fruit yield and irrigation water productivity}

The fruit yield obtained at various growth stages during the two growing seasons is presented in Table 2. For both seasons, there were no statistical differences in single fruit weight, volume, and fruit density for different deficit irrigation treatments $(p \leq 0.05)$. As regards total fruit and marketable yield, there was no adverse impact when deficit stress was applied during the vegetative stage $(p \leq 0.05)$, and the reduction in total fruit yield was only $2 \%$ for the 2016 season. The marketable yield for the T2 treatment was slightly higher than the control but with no statistical difference. When compared to the control, total fruit yield was reduced by 11 $\%$ and $21 \%$ for the T3 and T4 treatments, respectively, for the 2013 season; and by $15 \%$ and $30 \%$ for the 2016 season. The marketable yields for the $\mathrm{T} 3$ and $\mathrm{T} 4$ treatments were $9 \%$ and $17 \%$ lower than the marketable yield for the control treatment during the 2013 season, and $13 \%$ and $27 \%$ for the 2016 season, respectively.

The effect of the different irrigation treatments on irrigation water use efficiency (IWUE) and irrigation water productivity (IWP) is shown in Figures 4A and B. IWUE and IWP showed a similar trend for both seasons. Compared to the control treatment, IWUE for the T2 and T3 treatments increased by $8 \%$ and $10 \%$ for the 2013 season and $6 \%$ and $5 \%$ for the 2016 season, respectively. However, there was no statistical difference between the treatments $(p \leq 0.05)$, except that in 2016 the lowest IWUE was recorded for treatment T4. The highest IWP of $47.0 \mathrm{~kg} \mathrm{~m}^{-3}$ was obtained for the T3 treatment for the 2013 season and the lowest, $34.3 \mathrm{~kg} \mathrm{~m}^{-3}$, for the T4 treatment for the 2016 season. IWP for the other treatments varied between 35.0 and $46.3 \mathrm{~kg} \mathrm{~m}^{-3}$.

\section{Fruit quality traits}

The trends in fruit quality traits for the different irrigation treatments were the opposite to those for fruit yield except for fruit water content and the shape index (Figure 5A, B, C and D). For both seasons, differences in fruit firmness were observed between treatment $\mathrm{T} 3$ and the control $(p \leq 0.05$, Figure 5A). The greatest level of firmness was observed for a deficit during the flowering and fruit development phase for each season, but the deficit treatments did not affect the fruit water content when compared to the control for both seasons (Figure 5B). For the 2013 season, the T4 treatment improved redness considerably, whereas for the 2016 season, the color index increased for both the $\mathrm{T} 3$ and $\mathrm{T} 4$ treatments (Figure 5C). Compared to the control treatment, the deficit irrigation treatments did not affect the shape index for the 2013 season $(p \leq 0.05)$, but the T2, T3 and T4 treatments improved the shape index by $7 \%, 13 \%$ and $12 \%$, respectively, for the 2016 season (Figure 5D).
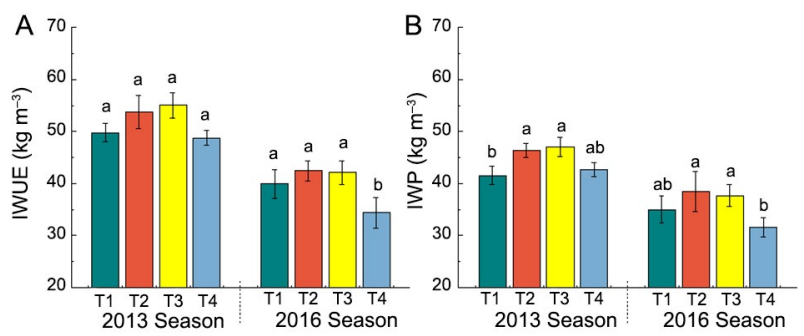

Figure 4 - (A) Irrigation water use efficiency (IWUE) and (B) irrigation water productivity (IWP) as influenced by drought stress during different growth stages in 2013 and 2016 seasons. Values are averages for three replicates and vertical bars represent \pm SE (Standard Error). Columns with the same letter represent values that are not significantly different according to the LSD test $(p \leq 0.05)$.

Table 2 - Weight, volume, and density for a single fruit and fruit yield for the different drought stress treatments.

\begin{tabular}{|c|c|c|c|c|c|c|c|}
\hline \multirow{2}{*}{ Year } & \multirow{2}{*}{ Treatment } & \multirow{2}{*}{ Irrigation amount } & \multicolumn{3}{|c|}{ Single fruit } & \multirow{2}{*}{ Total fruit yield } & \multirow{2}{*}{ Marketable fruit yield } \\
\hline & & & Weight & Volume & Density & & \\
\hline \multirow{5}{*}{2013} & & $\mathrm{~mm}$ & $g$ & $\mathrm{~cm}^{3}$ & $\mathrm{~g} \mathrm{~cm}^{-3}$ & \multicolumn{2}{|c|}{$\longrightarrow \mathrm{t} \mathrm{ha}^{-1}$} \\
\hline & $\mathrm{T} 1$ & 352 & $204.73 \pm 6.13 a$ & $203.72 \pm 8.82 a$ & $1.01 \pm 0.01 \mathrm{a}$ & $175.19 \pm 3.92 \mathrm{a}$ & $146.23 \pm 6.25 a$ \\
\hline & $\mathrm{T} 2$ & 321 & $196.39 \pm 8.57 a$ & $190.67 \pm 7.84 a$ & $1.03 \pm 0.02 a$ & $172.56 \pm 5.63 a$ & $148.71 \pm 4.41 \mathrm{a}$ \\
\hline & T3 & 282 & $201.59 \pm 7.35 a$ & $196.54 \pm 6.98 a$ & $1.03 \pm 0.05 a$ & $155.17 \pm 4.29 b$ & $132.58 \pm 5.14 a b$ \\
\hline & $\mathrm{T} 4$ & 282 & $193.35 \pm 3.68 a$ & $187.91 \pm 7.47 \mathrm{a}$ & $1.03 \pm 0.02 a$ & $137.59 \pm 3.55 c$ & $120.34 \pm 3.80 b$ \\
\hline \multirow{4}{*}{2016} & $\mathrm{~T} 1$ & 490 & $120.03 \pm 3.80 a$ & $119.14 \pm 3.30 a$ & $1.01 \pm 0.02 \mathrm{a}$ & $195.63 \pm 7.96 a$ & $171.36 \pm 7.35 a$ \\
\hline & $\mathrm{T} 2$ & 450 & $124.28 \pm 6.38 a$ & $122.28 \pm 4.24 a$ & $1.02 \pm 0.02 \mathrm{a}$ & $190.93 \pm 5.14 a$ & $172.82 \pm 10.04 a$ \\
\hline & T3 & 394 & $115.07 \pm 7.59 \mathrm{a}$ & $112.62 \pm 5.02 a b$ & $1.02 \pm 0.02 \mathrm{a}$ & $165.85 \pm 5.02 b$ & $148.56 \pm 4.90 b$ \\
\hline & T4 & 394 & $108.17 \pm 3.80 a$ & $106.02 \pm 1.72 b$ & $1.02 \pm 0.03 a$ & $135.33 \pm 6.61 c$ & $124.36 \pm 4.17 \mathrm{c}$ \\
\hline
\end{tabular}

Note: The treatment symbols of T1 to T4 are the same as in Figure 3. T1 is considered the control. Values with same letter represent values that are not significantly different at the 0.05 level of probability according to the LSD test. Each value is the mean $(n=3)$. 
Tomato taste and nutritional quality parameters, in terms of total soluble solids (TSS), soluble sugar (SS), organic acid (OA) and vitamin $\mathrm{C}(\mathrm{VC})$, under different irrigation treatments for the two seasons are presented in Figures $6 \mathrm{~A}, \mathrm{~B}, \mathrm{C}$ and D. For both seasons, the TSS improved for the T2, T3 and T4 treatments with an increase of $7-12 \%, 11-29 \%$ and $9-24 \%$, respectively, compared to the T1 control treatment (Figure 6A). The SS was also enhanced with a reduction of irrigation water during stage II and stage III (Figure 6B). It was higher for treatments T3 and T4 treatments in 2013 and for treatments T2, T3 and T4 in 2016 ( $p \leq 0.05)$. For the treatments with deficit irrigation the OA increased for the drought treatments compared to the control, except for the T2 treatment in 2016 ( $p \leq 0.05$, Figure 6C). The VC in treatments T2, T3 and T4 were $10 \%, 15 \%$ and $27 \%$ higher, respectively, than for the control treatment for 2013 and $9 \%, 25 \%$ and $34 \%$ higher, respectively, for 2016 (Figure 6D).

\section{Drought sensitivity of tomato yield and quality}

The trends for soil moisture content during both seasons for the different irrigation treatments were similar (Figure 7A, B, C, D, E and F). During the growing season, soil moisture was the highest for the control treatment. The reduction in irrigation during any growth stage decreased soil moisture. The plants that were subject to drought stress showed a decrease in ET. The mean values showed a difference in ET for the drought treatments compared to the control ( $p \leq 0.05)$. The lowest ET was found for treatment T3 at stage II and, compared to the control, it was lower by $18 \%$ and $16 \%$ in 2013 and 2016, respectively.
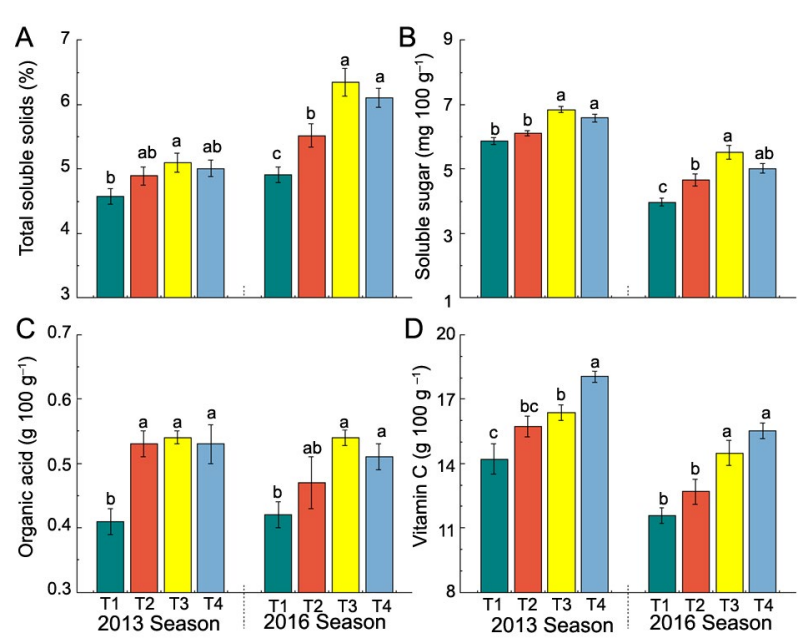

Figure 5 - (A) Firmness, (B) fruit water content, (C) color index and (D) shape index of tomato as influenced by drought stress during different growth stages in 2013 and 2016 seasons. Values are averages of three replicates and vertical bars represent \pm SE (Standard Error). Columns with the same letter represent values that are not significantly different according to the LSD test $(p \leq 0.05)$.
In general, the total amount of ET decreased with an increase in the number of stress days (SD). Compared to the well-watered treatment (T1), the SD increased by 10,18 and 13 days for stage I, stage II and stage III, respectively, in 2013, and by 6, 17 and 12 days in 2016 . There were similar tendencies in the relative yield reduction $(\mathrm{Fy})$, the ratio of the relative yield reduction to the stress days (Fy/SD), and the yield response factor (Ky) at different growth stages for both seasons (Table 3). The largest values of drought sensitivity indexes were obtained during stage III, followed by stage II, and the lowest values during stage I. Moreover, the tomato yield sensitivity indexes, especially for the value of Fy/SD, were close to zero during stage I.

The drought sensitivity indexes of fruit quality parameters during different growth stages are shown in Table 4. The largest Fq values of TSS, SS and OA were recorded at stage II for both seasons, followed by those at stage III, and the lowest values were obtained at stage I. There were no differences in Fq/SD, TSS, SS and OA between stage II and stage III, but for VC, the Fq values were seen to be higher at stage III than at stage I in both seasons. The highest value of $\mathrm{Fq} / \mathrm{SD}$ was obtained in VC at stage III in 2016, which implies that the concentration of VC is more susceptible to drought stress during stage III. As regards the fruit quality response factor, the $\mathrm{K}_{\text {TSS }}$ value was highest at stage III in 2013 and at stage I in 2016 (Table 5). The SS concentration was mainly affected by drought stress at stage II in 2013 and stage I in 2016. The highest $\mathrm{K}_{\mathrm{OA}}$ value was observed at stage $\mathrm{I}$ in 2013. The VC concentration was that most susceptible to drought stress at stage III for both seasons.

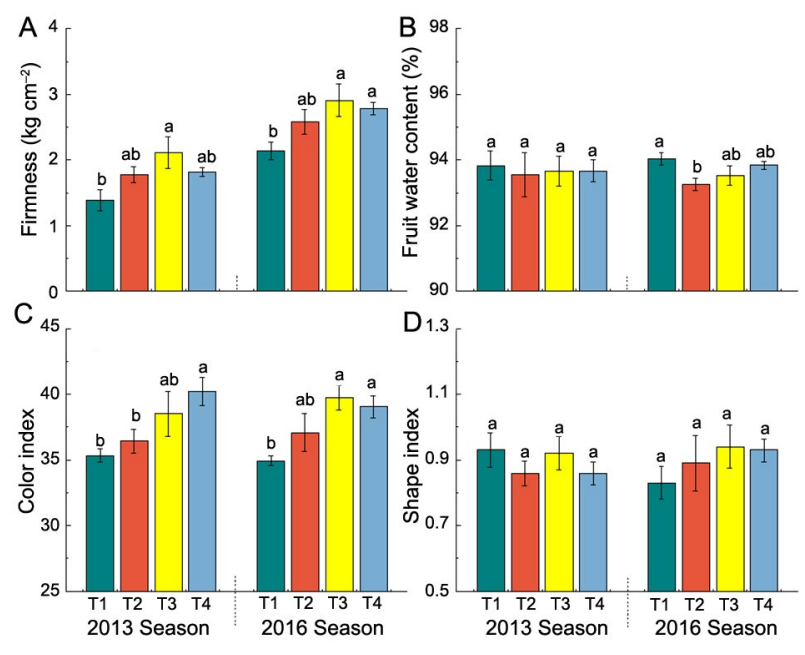

Figure 6 - (A) Total soluble solids, (B) soluble sugar, (C) organic acid and (D) vitamin $C$ as influenced by drought stress during different growth stages in 2013 and 2016 seasons. Values are averages of three replicates and vertical bars represent \pm SE (Standard Error). Columns with the same letter represent values that are not significantly different according to the LSD test $(p \leq 0.05)$. 

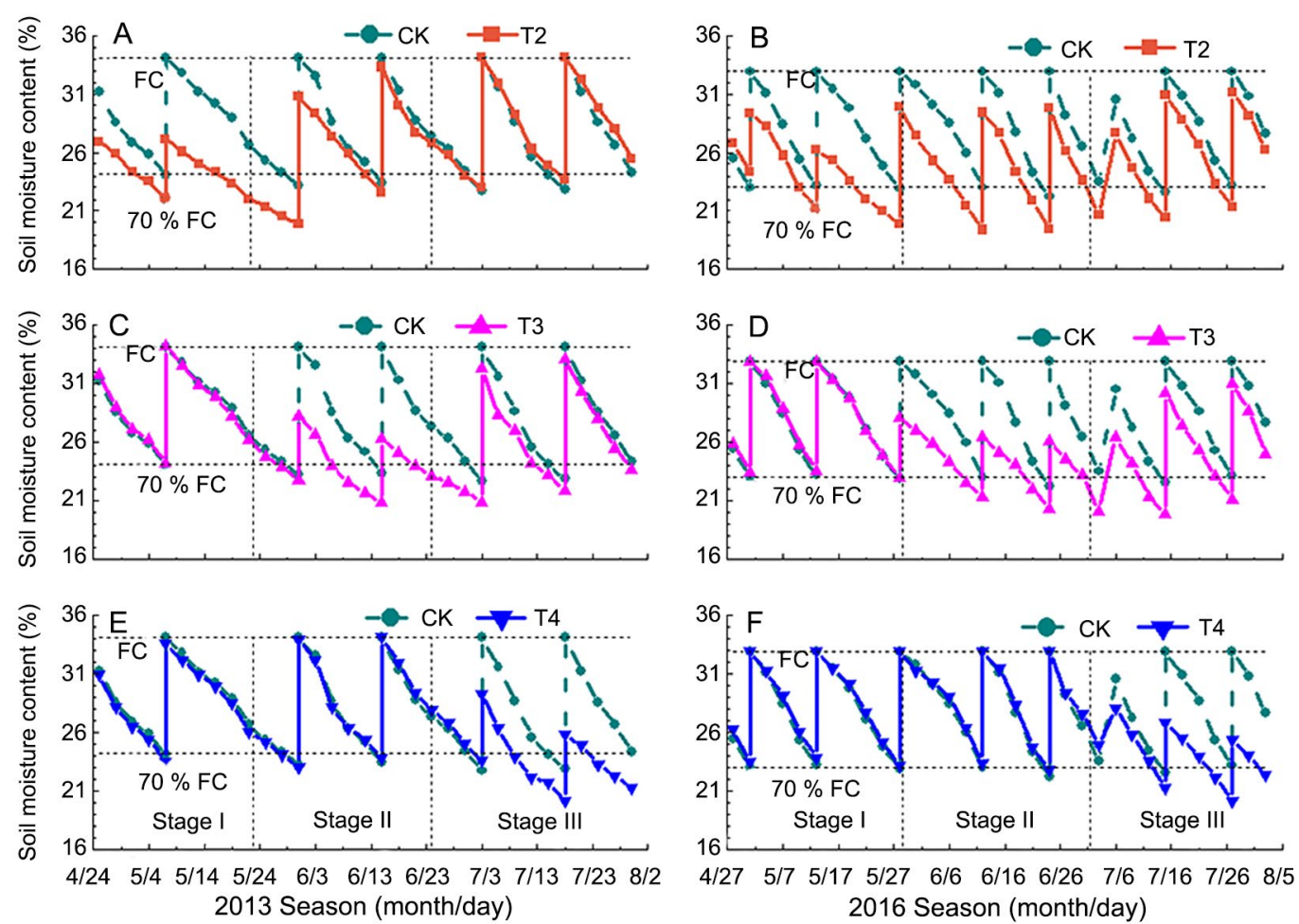

Figure 7 - Trends of volumetric soil moisture content between the control and drought stressed treatments at stage I (A-B), stage II (C-D), stage III (E-F) during the 2013 and 2016 growing seasons. Lower constant horizontal dash line indicates lower irrigation limit, $70 \%$ field capacity (70\% FC). Upper constant horizontal dash line indicates upper irrigation limit, $100 \%$ field capacity (FC). Vertical dash lines indicate divisions between growth stages. The T1 treatment is the control (CK).

Table 3 - Total evapotranspiration (ET), number of stress days (SD), relative yield reduction (Fy), ratio of the relative yield reduction to the number of stress days (Fy/SD), and yield response factor $(\mathrm{Ky})$ for the different drought stress treatments.

\begin{tabular}{|c|c|c|c|c|c|c|c|c|c|c|}
\hline \multirow{2}{*}{ Treatment } & \multicolumn{2}{|c|}{ ET (mm) } & \multicolumn{2}{|c|}{$\mathrm{SD}$ (d) } & \multicolumn{2}{|c|}{ Fy } & \multicolumn{2}{|c|}{$\mathrm{Fy} / \mathrm{SD}$} & \multicolumn{2}{|c|}{ Ky } \\
\hline & 2013 & 2016 & 2013 & 2016 & 2013 & 2016 & 2013 & 2016 & 2013 & 2016 \\
\hline T1 & $358.0 \pm 7.0 \mathrm{a}$ & $475.5 \pm 10.6 \mathrm{a}$ & & & & & & & & \\
\hline T2 & $319.2 \pm 3.9 b$ & $444.8 \pm 7.4 b$ & $10.3 \pm 1.0 \mathrm{c}$ & $6.1 \pm 1.5 \mathrm{c}$ & $0.03 \pm 0.02 c$ & $0.03 \pm 0.01 \mathrm{c}$ & $0.003 \pm 0.001 b$ & $0.004 \pm 0.002 c$ & $0.27 \pm 0.14 b$ & $0.37 \pm 0.24 b$ \\
\hline T3 & $292.2 \pm 4.7 \mathrm{c}$ & $397.3 \pm 7.4 \mathrm{c}$ & $17.5 \pm 1.2 \mathrm{a}$ & $15.6 \pm 1.5 \mathrm{a}$ & $0.11 \pm 0.02 b$ & $0.15 \pm 0.03 b$ & $0.006 \pm 0.001 b$ & $0.010 \pm 0.001 b$ & $0.61 \pm 0.09 b$ & $0.91 \pm 0.07 b$ \\
\hline T4 & $308.7 \pm 3.1 b$ & $414.8 \pm 5.3 c$ & $13.1 \pm 0.8 b$ & $12.1 \pm 1.1 \mathrm{~b}$ & $0.21 \pm 0.02 a$ & $0.31 \pm 0.03 \mathrm{a}$ & $0.016 \pm 0.001 \mathrm{a}$ & $0.025 \pm 0.001 \mathrm{a}$ & $1.56 \pm 0.09 a$ & $2.41 \pm 0.11 \mathrm{a}$ \\
\hline
\end{tabular}

Table 4 - Relative quality improvement $(\mathrm{Fq})$, ratio of drought sensitivity to the number of stress days (Fq/SD) of fruit quality parameters for the different growth stages.

\begin{tabular}{|c|c|c|c|c|c|c|c|c|c|}
\hline \multirow{2}{*}{ Season } & \multirow{2}{*}{$\begin{array}{l}\text { Growth } \\
\text { stages }\end{array}$} & \multicolumn{2}{|c|}{ Total soluble solids } & \multicolumn{2}{|c|}{ Soluble sugar } & \multicolumn{2}{|c|}{ Organic acid } & \multicolumn{2}{|c|}{ Vitamin C } \\
\hline & & $\mathrm{Fq}$ & $\mathrm{Fq} / \mathrm{SD}$ & $\mathrm{Fq}$ & $\mathrm{Fq} / \mathrm{SD}$ & $\mathrm{Fq}$ & $\mathrm{Fq} / \mathrm{SD}$ & $\mathrm{Fq}$ & $\mathrm{Fq} / \mathrm{SD}$ \\
\hline \multirow{3}{*}{2013} & stage I & $0.070 \pm 0.031 a$ & $0.006 \pm 0.000 a$ & $0.043 \pm 0.014 b$ & $0.004 \pm 0.000 b$ & $0.293 \pm 0.051 a$ & $0.028 \pm 0.002 a$ & $0.106 \pm 0.033 b$ & $0.010 \pm 0.002 b$ \\
\hline & stage II & $0.116 \pm 0.033 a$ & $0.006 \pm 0.000 a$ & $0.169 \pm 0.016 a$ & $0.009 \pm 0.000 \mathrm{a}$ & $0.317 \pm 0.026 a$ & $0.018 \pm 0.000 \mathrm{~b}$ & $0.152 \pm 0.026 b$ & $0.009 \pm 0.001 b$ \\
\hline & stage III & $0.096 \pm 0.028 a$ & $0.007 \pm 0.000 a$ & $0.123 \pm 0.018 a$ & $0.009 \pm 0.000 a$ & $0.293 \pm 0.077 a$ & $0.022 \pm 0.004 a b$ & $0.270 \pm 0.019 a$ & $0.021 \pm 0.001 a$ \\
\hline \multirow{3}{*}{2016} & stage I & $0.124 \pm 0.037 b$ & $0.018 \pm 0.004 a$ & $0.174 \pm 0.094 a$ & $0.025 \pm 0.009 a$ & $0.119 \pm 0.101 \mathrm{a}$ & $0.015 \pm 0.002 \mathrm{a}$ & $0.096 \pm 0.050 \mathrm{~b}$ & $0.014 \pm 0.005 b$ \\
\hline & stage II & $0.293 \pm 0.044 a$ & $0.018 \pm 0.001 \mathrm{a}$ & $0.388 \pm 0.109 a$ & $0.024 \pm 0.005 a$ & $0.286 \pm 0.025 a$ & $0.018 \pm 0.001 \mathrm{a}$ & $0.251 \pm 0.050 \mathrm{ab}$ & $0.016 \pm 0.002 b$ \\
\hline & stage III & $0.244 \pm 0.029 a$ & b $0.019 \pm 0.001 a$ & $0.264 \pm 0.066 a$ & $0.020 \pm 0.004 a$ & $0.214 \pm 0.050 a$ & $0.017 \pm 0.003 a$ & $0.341 \pm 0.032 \mathrm{a}$ & $0.026 \pm 0.001 a$ \\
\hline
\end{tabular}

Note: Values with same letter represent values that are not significantly different at the 0.05 level of probability according to the LSD test. Each value is the mean $(n=3)$. 
Table 5 - Fruit quality response factor (Kq) for the different growth stages for the 2013 and 2016 seasons.

\begin{tabular}{|c|c|c|c|c|c|c|c|c|}
\hline \multirow{2}{*}{ Growth stages } & \multicolumn{2}{|c|}{$\mathrm{K}_{\mathrm{TSS}}$} & \multicolumn{2}{|c|}{$\mathrm{K}_{\mathrm{sS}}$} & \multicolumn{2}{|l|}{$\mathrm{K}_{\mathrm{OA}}$} & \multicolumn{2}{|c|}{$\mathrm{K}_{\mathrm{vc}}$} \\
\hline & 2013 & 2016 & 2013 & 2016 & 2013 & 2016 & 2013 & 2016 \\
\hline stage I & $0.606 \pm 0.206 a$ & $1.98 \pm 0.35 a$ & $0.377 \pm 0.087 b$ & $2.42 \pm 0.87 a$ & $2.67 \pm 0.196 a$ & $1.46 \pm 1.12 \mathrm{a}$ & $0.937 \pm 0.222 b$ & $1.27 \pm 0.49 b$ \\
\hline stage II & $0.612 \pm 0.130 a$ & $1.79 \pm 0.11 \mathrm{a}$ & $0.916 \pm 0.027 a$ & $2.28 \pm 0.45 a$ & $1.73 \pm 0.080 b$ & $1.74 \pm 0.01 \mathrm{a}$ & $0.816 \pm 0.079 b$ & $1.51 \pm 0.18 b$ \\
\hline stage III & $0.681 \pm 0.154 a$ & $1.91 \pm 0.12 \mathrm{a}$ & $0.885 \pm 0.082 a$ & $2.02 \pm 0.35 a$ & $2.08 \pm 0.420 a b$ & $1.65 \pm 0.27 a$ & $1.964 \pm 0.060 a$ & $2.68 \pm 0.13 a$ \\
\hline
\end{tabular}

Note: $\mathrm{K}_{\mathrm{TSS}}=$ Total soluble solids response factor; $\mathrm{K}_{\mathrm{SS}}=$ Soluble sugar response factor; $\mathrm{K}_{\mathrm{OA}}=$ Organic acid response factor; $\mathrm{K}_{\mathrm{vC}}=$ Vitamin $\mathrm{C}$ response factor. Values with same letter represent values that are not significantly different at the 0.05 level of probability according to the LSD test. Each value is the mean ( $n=3$ ).

\section{Discussion}

Tomato is considered to be a crop that has a high water demand but is moderately tolerant to drought stress (Karlberg et al., 2007). Irrigation is the most important source of water for tomato in high tunnels, making it one of the key determinants to affect both fruit yield and quality. Many studies have shown that, in general, deficit irrigation depresses tomato fruit yield under drought stress conditions (Jensen et al., 2010; Topcu et al., 2007), and that the tolerance of tomato to water deficit depends on the cultivar, the growth stage at which the deficit occurs, and the severity of the drought stress (Patanè and Cosentino, 2010; Patanè et al., 2011).

In this study, deficit irrigation treatments reduced total fruit and marketable yield during flowering and fruit development, and the fruit ripening stages; drought stress during these two stages has been found to lead to flower abortion (Pulupol et al., 1996; Zegbe et al., 2006). It is likely that deficit irrigation for treatment T2 did not affect total fruit and marketable yield $(p \leq$ $0.05)$ compared to the well-irrigated treatment, as studies have shown that water limitations during the vegetative stage occur too early to affect fruit yield (Chen et al., 2013; Nangare et al., 2016). It has been reported that deficit irrigation during the vegetative period could enhance root growth, which may stimulate water and nutrient transfer to the vegetative parts of the plant (Nangare et al., 2016).

Fruit firmness and fruit water content are concerns for both growers and consumers because they impact the storage quality of tomato (Kader, 2008). In this study, water deficit, especially during the flowering and development stage, enhanced fruit firmness ( $p$ $\leq 0.05$ ) similar to the findings of Patanè and Cosentino (2010). Smaller fruits tend to be firmer due to an increase in total soluble solid content and cellular density (Shao et al., 2015a), which was confirmed by the results in our study. The difference in fruit water content between different water regimes was not significant, which was consistent with the analysis of the single fruit density ( $p \leq 0.05$, Table 2).

Fruit appearance traits, including size, color and shape index, are the most relevant quality parameters for consumers (Shao et al., 2015a). In this study, there were no statistical differences $(p \leq 0.05)$ in the shape index of tomato subjected to various water deficit treatments, which implied that the fruit shape was mainly determined by the genetics of the cultivar (Shao et al., 2015a). The red color of tomatos is principally associated with the lycopene content and generally considered the most important attribute that determines product quality (Nangare et al., 2016; Simpson et al., 2008). We observed that restricting the water supply at each growth stage promoted an increase in color index, similar to that found by Nuruddin et al. (2003). Abiotic stresses, such as salt or drought, raise the ethylene content of tomato, which then increases the lycopene content and carotenoid concentration, thereby enhancing the color of the tomato fruit (Basiouny et al., 1994; Wang et al., 2011).

Tomato taste and nutritional quality are largely determined by TSS, OA, SS and VC (Dorais et al., 2001). Many studies have reported that deficit irrigation can enhance the nutritional quality of the fruit, depending on the period and degree of drought stress (Chen et al., 2014; Patanè and Cosentino, 2010; Pulupol et al., 1996). In our study the concentration of TSS and SS increased with drought stress at each growth stage. Similarly, Chen et al. (2013) found that limited water, especially during the fruit ripening period, improved the fruit quality of tomatoes, increasing TSS and SS. A basic strategy for stress mitigation is to induce drought stress and enhance reverse metabolism (Cowan et al., 2005). Accelerated senescence leads to increased levels of hexokinase, which induce higher sugar content in leaves (Dai et al., 1999). Ripening tomatoes are a strong sugar sink, which explains our findings of an increase in TSS and SS for the drought stress treatments, particularly during the fruit ripening phase. This study showed that all deficit treatments increased the OA concentration, but no statistical difference ( $p \leq 0.05)$ was found between these deficit treatments. A similar trend for fruit acidity in response to a reduction in the water supply was reported by Mitchell et al. (1991). The vitamin $\mathrm{C}$ concentration increased under water shortage at each stage, especially during fruit ripening, as VC is positively influenced by irrigation deficits during the ripening period (Chen et al., 2014; Patanè et al., 2011), and VC synthesis is boosted at this stage by higher sugar concentration with water reduction (Horst et al., 2001).

The effect of deficit irrigation on tomato yield and fruit quality has been widely studied (Favati et al., 2009; Mitchell et al., 1991; Patanè and Cosentino, 2010; Shao et al., 2015a). However, in order to achieve opti- 
mal tomato production, the impact of drought during different growth phases on overall tomato yield and quality was studied. The relative yield reduction and fruit quality improvement $(F)$, the ratio of $F$ to the number of stress days $(F / S D)$ and the response factor $(K)$ were calculated. These water deficit sensitivity indexes quantified the responsiveness of tomato yield and quality to drought stress during each growth phase. The largest values of sensitivity indexes were observed at stage III, indicating that yield was susceptible to drought stress during this phase, similar to that reported for tomatos grown under greenhouse conditions (Chen et al., 2014). The sensitivity indexes were smallest for stage I and close to zero, implying that drought stress was not significant in terms of yield reduction. Similarly, other researchers have reported that drought stress had no adverse effect on tomato yield during the vegetative stage (Zegbe et al., 2006; Chen et al., 2013; Kuşçu et al., 2014). Seasonal variation patterns of Fy/ SD and Ky values were in line with the natural growth principle of tomato (Nuruddin et al., 2003). Deficit irrigation occurring early in the crop cycle allowed plants to recover from stress using different mechanisms (Chen et al., 2013; Wu et al., 2018).

Unlike the relationship between tomato yield and ET, tomato quality was negatively correlated with ET during the entire growing season and for each growth phase (Favati et al., 2009; Kuşçu et al., 2014). Similar to the sensitivity indexes for yield, the higher absolute values of drought sensitivity indexes denote the higher sensitivity of the fruit quality parameters to drought stress. In this study, TSS, SS and OA were sensitive to drought stress at stages II and III with similar F/SD and Kq values, and VC was also sensitive to drought stress at stage II but more at stage III. Chen et al. (2014) reported that tomato quality parameters such as TSS, SS, $\mathrm{OA}$ and VC were especially affected by drought stress at stage III. The slightly different results obtained in this study might be due to a variety of growth conditions, water management, and the indeterminate nature of the tomato crop.

Drought stress sensitivity indexes could be improved by considering a compromise between tomato yield, fruit quality and water use efficiency. In this study, satisfactory fruit yield and quality with smaller drought sensitivity were obtained for a water deficit at stage I. Although the strategies of deficit irrigation at stage III improved the quality of tomato fruit, there was a high risk of jeopardizing the marketable fruit yield. However, there was only one level of drought stress during the different developmental phases. Therefore, there is a need for additional experiments on the influence of different degrees of drought stress to be conducted to determine potential responses. Further studies should also investigate water management during tomato production in order to optimize the quantitative relationship between tomato yield, fruit quality and water consumption.

\section{Conclusions}

The results of this study showed that fruit yield decreased as a result of deficit irrigation during the fruit ripening stage, though the rate of decrease was less during the flowering and fruit development stage. Fruit quality parameters improved with drought stress during the growing season. Final yield was most sensitive to drought stress during the fruit ripening stage while the total soluble solids, soluble sugar and vitamin $\mathrm{C}$ were sensitive to water deficit during both the flowering and fruit development stage and the fruit ripening stage. The findings from this study imply that deficit irrigation during the vegetative phase could be applied to enhancing fruit quality without jeopardizing the tomato yield while improving water use efficiency.

\section{Acknowledgments}

This research was supported by the National Nature \& Science Foundation of China (No. 51279059), the Supporting Program of the Postgraduate Research \& Practice Innovation Program of Jiangsu Province (KYCX17_0432), Jiang Su Qing Lan, the Fundamental Research Funds for the Central Universities (2017B688X14), Jiang Su Qing Lan, and the project of the Priority Academic Program Development of Jiangsu Higher Education Institutions.

\section{Authors' Contributions}

Conceptualization: Cui, J.; Shao, G. Design of methodology: Cui, J.; Shao, G. Data acquisition: Cui, J.; Lu, J.; Keabetswe, L. Data analysis: Cui, J.; Lu, J.; Keabetswe, L.; Hoogenboom, G. Writing and editing: Cui, J.; Shao, G.; Keabetswe, L.; Hoogenboom, G.

\section{References}

Allen, R.G.; Pereira, L.S.; Howell, T.A.; Jensen, M.E. 2011. Evapotranspiration information reporting. I. Factors governing measurement accuracy. Agricultural Water Management 98: 899-920.

Basiouny, F.M.; Basiouny, K.; Maloney, M. 1994. Influence of water stress on abscisic acid and ethylene production in tomato under different PAR levels. Journal of Horticultural Science 69: 535-541.

Chen, J.; Kang, S.; Du, T.; Guo, P.; Qiu, R.; Chen, R.; Gu, F. 2014. Modeling relations of tomato yield and fruit quality with water deficit at different growth stages under greenhouse condition. Agricultural Water Management 146: 131-148.

Chen, J.; Kang, S.; Du, T.; Qiu, R.; Guo, P.; Chen, R. 2013. Quantitative response of greenhouse tomato yield and quality to water deficit at different growth stages. Agricultural Water Management 129: 152-162.

Cowan, A.K.; Freeman, M.; Bjorkman, P.O.; Nicander, B.; Sitbon, F.; Tillberg, E. 2005. Effects of senescence-induced alteration in cytokinin metabolism on source-sink relationships and ontogenic and stress-induced transitions in tobacco. Planta 221: 801-814. 
Dai, N.; Schaffer, A.; Petreikov, M.; Shahak, Y.; Giller, Y.; Ratner, K. 1999. Overexpression of Arabidopsis hexokinase in tomato plants inhibits growth, reduces photosynthesis, and induces rapid senescence. Plant Cell 11: 1253-1266.

Dorais, M.; Papadopoulos, A.P.; Gosselin, A. 2001. Influence of electric conductivity management on greenhouse tomato yield and fruit quality. Agronomie 4: 367-383.

Favati, F.; Lovelli, S.; Galgano, F.; Miccolis, V.; Tommaso, T.D.; Candido, V. 2009. Processing tomato quality as affected by irrigation scheduling. Scientia Horticulturae 122: 562-571.

Horst, W.J.; Schenk, M.K.; Bürkert, A.; Claassen, N.; Flessa, H.; Frommer, W.B.; Goldbach, H.; Olfs, H.W.; Mheld, V.R.; Sattelmacher, B.; Schmidhalter, U.; Schubert, S.; Wirén, N.V.; Wittenmayer, L.; Hler, U.V.; Krumbein, A.; Kosegarten, H. 2001. Different Water Supply Influences Growth and Fruit Quality in Tomato (Lycopersicon esculentum L.). Springer, Amsterdam, Netherlands.

Jensen, C.R.; Battilani, A.; Plauborg, F.; Psarras, G.; Chartzoulakis, K.; Janowiak, F.; Stikic, R.; Jovanovic, Z.; Li, G.; Qi, X.; Liu, F.; Jacobsen, S.; Andersen, M.N. 2010. Deficit irrigation based on drought tolerance and root signalling in potatoes and tomatoes. Agricultural Water Management 98: 403-413.

Kader, A.A. 2008. Flavor quality of fruits and vegetables. Journal of the Science of Food and Agriculture 88: 1863-1868.

Kahn, B.A.; Damicone, J.P. 2008. Kaolin particle film product applications before harvest begins may not improve marketable yields of fresh tomatoes. Horttechnology 42: 1010.

Karlberg, L.; Rockström, J.; Annandale, J.G.; Steyn, J.M. 2007. Low-cost drip irrigation: a suitable technology for southern Africa? Agricultural Water Management 89: 59-70.

Ku çu, H.; Turhan, A.; Demir, A.O. 2014. The response of processing tomato to deficit irrigation at various phenological stages in a sub-humid environment. Agricultural Water Management 133: 92-103.

Mitchell, J.; Shennan, C.; Grattan, S.R.; May, D. 1991. Tomato fruit yields and quality under water deficits and salinity. Journal of the American Society for Horticultural Science 2: 215-221.

Mogensen, V.O.; Jensen, H.E.; Rab, M.A. 1985. Grain yield, yield components, drought sensitivity and water use efficiency of spring wheat subjected to water stress at various growth stages. Irrigation Science 6: 131-140.

Nangare, D.D.; Singh, Y.; Kumar, P.S.; Minhas, P.S. 2016. Growth, fruit yield and quality of tomato (Lycopersicon esculentum Mill.) as affected by deficit irrigation regulated on phenological basis. Agricultural Water Management 171: 73-79.

Nuruddin, M.M.; Madramootoo, C.A.; Dodds, G.T. 2003. Effects of water stress at different growth stages on greenhouse tomato yield and quality. Horticultural Science 38: 1389-1393.
Patanè, C.; Cosentino, S.L. 2010. Effects of soil water deficit on yield and quality of processing tomato in a Mediterranean climate. Agricultural Water Management 97: 131-138.

Patanè, C.; Tringali, S.; Sortino, O. 2011. Effects of deficit irrigation on biomass, yield, water productivity and fruit quality of processing tomato under semi-arid Mediterranean climate conditions. Scientia Horticulturae 129: 590-596.

Peet, M.M. 1992. Fruit cracking in tomato. Horttechnology 2: 216-223.

Pulupol, L.U.; Behboudian, M.H.; Fisher, K.J. 1996. Growth, yield, and postharvest attributes of glasshouse tomatoes produced under deficit irrigation. Horticultural Science 31: 926-929.

Qi, H.; Li, T.; Zhang, J.; Wang, L.; Chen, Y. 2003. Effects on sucrose metabolism, dry matter distribution and fruit quality of tomato under water deficit. Agricultural Sciences in China 2: $1253-1258$

Shao, G.C.; Deng, S.; Liu, N.; Wang, M.H.; She, D.L. 2015a. Fruit quality and yield of tomato as influenced by rain shelters and deficit irrigation. Journal of Agricultural Science and Technology 17: 691-704.

Shao, G.; Yuan, M.; Liu, N.; Ji, J.; Yu, W. 2015b. Effect of rain shelters and drought on leaf water status and photosynthetic parameters in tomato. Archives of Agronomy and Soil Science 61: 1273-1288.

Simpson, B.K.; Nollet, L.M.L.; Toldrá, F.; Benjakul, S.; Paliyath, G.; Hui, Y.H. 2008. Food Biochemistry and Food Processing. 2ed. Blackwell, Oxford, UK.

Topcu, S.; Kirda, C.; Dasgan, Y.; Kaman, H.; Cetin, M.; Yazici, A.; Bacon, M.A. 2007. Yield response and N-fertiliser recovery of tomato grown under deficit irrigation. European Journal of Agronomy 26: 64-70.

Wang, F.; Kang, S.; Du, T.; Li, F.; Qiu, R. 2011. Determination of comprehensive quality index for tomato and its response to different irrigation treatments. Agricultural Water Management 98: 1228-1238.

William, J.L. 2009. Overview of the use of high tunnels worldwide. HortTechnology 19: 25-29.

Wu, X.; Tang, Y.; Li, C.; McHugh, A.; Li, Z.; Wu, C. 2018. Individual and combined effects of soil waterlogging and compaction on physiological characteristics of wheat in southwestern China. Field Crops Research 215: 163-172.

Zegbe, J.A.; Behboudian, M.H.; Clothier, B.E. 2006. Responses of 'Petopride' processing tomato to partial rootzone drying at different phenological stages. Irrigation Science 25: 85. 